\title{
Instituições participativas e desenho institucional: algumas considerações sobre a variação da participação no Brasil democrático
}

\author{
Leonardo Avritzer \\ Departamento de Ciência Política \\ Universidade Federal de Minas Gerais
}

\begin{abstract}
Resumo: $O$ autor analisa as instituições participativas (orçamentos participativos, conselhos de políticas e planos diretores municipais) surgidas na democracia brasileira recente e aponta para suas diferenças devidas a desenhos institucionais diferenciados. Estes variam na maneira como a participação se organiza; na maneira como o Estado se relaciona com a participação e na maneira como a legislação exige do governo a implementação ou não da participação e o autor mostra esta variação através da análise destas práticas em diferentes cidades brasileiras (Porto Alegre, São Paulo, Belo Horizonte e Salvador). A análise dos diferentes desenhos participativos mostra que o orçamento participativo é a prática mais democratizante, mas também a mais vulnerável à vontade da sociedade política; indica ainda a importância da variação do contexto para a efetividade da participação.
\end{abstract}

Palavras-chave: instituições participativas, desenho institucional, democracia brasileira, orçamento participativo

\begin{abstract}
The author analyses the participative institutions (participative budgets, local councils of politics and managing plans) emerged in the recent Brazilian democracy and he points to their differences due the distinct institutional designs. These institutions vary in the way as the participation is organized; in the way as the State is related to the participation and in the way the law imposes the government to adopt participative formula. The author shows this variation in different Brazilian cities (Porto Alegre, São Paulo, Belo Horizonte e Salvador) and the analysis shows that the participative budget is the more democratic but also the most vulnerable form that suffers the pressure of political society. The analysis also indicates the importance of the context variation for the effectiveness of the participation.
\end{abstract}

Key words: participative institutions, institutional design, Brazilian democracy, participative budget 


\section{Introdução}

O Brasil se transformou ao longo do século XX de um país de baixa propensão associativa e poucas formas de participação da população de baixa renda (KOWARICK, 1973; SINGER e BRANDT, 1980; AVRITZER, 2000), em um dos países com o maior número de práticas participativas. O surgimento do orçamento participativo em Porto Alegre despertou atenção de atores do norte e do sul sobre as novas formas de participação geradas pela democratização brasileira (SANTOS, 1998; AVRITZER, 2002a; BAIOCCHI, 2005; SINTOMER, 2005). Ao mesmo tempo em que o orçamento participativo surgiu em Porto Alegre e se estendeu para mais de 170 cidades (AVRITZER, 2006) surgiram também duas outras formas adicionais de participação no Brasil democrático resultantes do processo constituinte e sua posterior regulamentação. Os conselhos de políticas surgiram como resultado da Lei Orgânica da Saúde (LOS) e da assistência social (LOAS) e, como resultado do capítulo das políticas urbanas do processo constituinte e sua regulamentação em 2001 através do Estatuto da Cidade, começaram a proliferar durante a última década os assim chamados "Planos Diretores Municipais". Estes últimos se tornaram obrigatórios em todas as cidades com mais de 20.000 habitantes. Assim, temos hoje no país o que podemos denominar de uma infra-estrutura da participação bastante diversificada na sua forma e no seu desenho.

Quando analisamos detalhadamente os orçamentos participativos, os conselhos de políticas e os planos diretores municipais visualizamos uma variedade de instituições participativas expressa através de desenhos institucionais diferenciados. No caso dos orçamentos participativos, eles constituem aquilo que a literatura denomina de desenhos participativos de baixo para cima (FUNG e WRIGHT, 2003; BAIOCCHI, 2003). Eles são uma forma aberta de livre entrada e participação de atores sociais capaz de gerar mecanismos de representação da participação. No caso dos conselhos de políticas, eles constituem desenhos institucionais de partilha do poder e são constituídos pelo próprio Estado, com representação mista de atores da sociedade civil e atores estatais. E, por fim, os planos diretores municipais, através da obrigatoriedade das audiências públicas, constituem um terceiro tipo que denominamos desenho institucional de ratificação. É importante perceber que estes desenhos variam em pelo menos três aspectos: na maneira como a participação se organiza; na maneira como o Estado se relaciona com a participação e na maneira como a legislação exige do governo a implementação ou não da participação. O objetivo deste artigo é comparar estes desenhos nestas três dimensões; ele está dividido em quatro partes: na primeira delas fazemos breves considerações sobre desenho institucional e participação e nas três seções seguintes abordamos cada um dos tipos de desenho institucional 
AVRITZER, L. Instituições participativas e desenho institucional...

mostrando a sua variação em diferentes contextos. Nas conclusões, mostramos o contexto no qual o processo participativo instaurado se torna mais efetivo.

\section{Desenho institucional participativo: algumas reflexões heterodoxas}

A teoria democrática da segunda metade do século $X X$ operou com um conceito bastante limitado de instituições políticas. Para ela, o elemento central da institucionalidade esteve centrado na existência de uma legislação formal acerca do funcionamento das instituições. As instituições são definidas de forma convencional como um conjunto de normas e de regras que estruturam a ação social e política (MEYER e ROWAN, 1991, p.41; HELMKE e LEVITSKI, 2006). Ainda que diversos desses autores admitam a presença de regras informais no interior das instituições políticas, a literatura sobre o assunto se concentrou predominantemente em regras informais no interior de instituições políticas formalmente ou legalmente constituídas, tais como parlamentos, partidos e poder judiciário (HELMKE e LEVITSKY, 2006). Dois conjuntos de críticas podem ser feitas a esta literatura: a primeira crítica diz respeito ao fato de um conjunto de instituições participativas no Brasil não estão nem formal nem legalmente constituídas e, no entanto, pautam um conjunto de comportamentos e expectativas importantes dos atores sociais (AVRITZER, 2009, no prelo). A segunda crítica está relacionada à própria abrangência do conceito de instituição política que, via de regra, não trata das práticas participativas, mas apenas das instituições resultantes do processo de autorização da representação (PITKIN, 1967). Implicitamente, ao excluir as formas de participação do hall das instituições, esta literatura continua operando com uma oposição entre participação e institucionalização (HUNTINGTON, 1969) que há muito tempo não é capaz de gerar um entendimento adequado do fenômeno da participação.

Em contraposição a essa maneira de conceber a participação lançamos o conceito de instituições participativas. Por instituições participativas entendemos formas diferenciadas de incorporação de cidadãos e associações da sociedade civil na deliberação sobre políticas (AVRITZER, 2009, no prelo). É possível diferenciar pelo menos três formas através das quais os cidadãos ou associações da sociedade civil podem participar do processo de tomada de decisão política: a primeira destas formas é o que denominamos de desenho participativo de baixo para cima (FUNG e WRIGHT, 2003 e BAIOCCHI, 2003). Neste caso, do qual o orçamento participativo no Brasil é o exemplo mais conhecido, há a livre entrada de qualquer cidadão no processo participativo e as formas institucionais da participação são constituídas de baixo para cima. Assim, mais uma vez no caso do orçamento participativo, podemos pensar nas eleições de delegados pela população e na eleição de conselheiros pela população. Ambos os processos ocorrem de baixo para cima (SANTOS, 1998; 
ABERS, 2000; AVRITZER, 2002b). Afirmar que o orçamento participativo ocorre de baixo para cima não significa diminuir a iniciativa do Estado em implantá-lo, mas apenas enfatizar que esta iniciativa cria uma institucionalidade de baixo para cima ${ }^{1}$. A segunda maneira como instituições participativas podem se constituir é através de um processo de partilha do poder, isto é, através da constituição de uma instituição na qual atores estatais e atores da sociedade civil participam simultaneamente. Este arranjo se diferencia do anterior por dois motivos principais: porque não incorpora um número amplo de atores sociais e porque é determinado por lei e pressupõe sanções em casos da não instauração do processo participativo². Há ainda um terceiro formato de instituição participativa no qual ocorre um processo de ratificação pública, ou seja, no qual se estabelece um processo em que os atores da sociedade civil não participam do processo decisório, mas são chamados a referendá-lo publicamente.

Se analisarmos de forma detalhada os três tipos de arranjos participativos podemos diferenciá-los a partir de três variáveis: iniciativa na proposição do desenho, organização da sociedade civil na área em questão e vontade política do governo em implementar a participação. Cada uma das três variáveis se expressa de forma diferente nas três instituições participativas em questão, tal como mostramos a frente. No caso do OP, a sua experiência em Porto Alegre mostra, tal como a literatura já apontou, a iniciativa do governo em propor o desenho (SANTOS, 2002; ABERS, 2000); uma forte organização prévia da sociedade civil (AVRITZER, 2002b; BAIOCCHI, 2005) e a persistência da vontade política do governo em implementar a política participativa (WAMPLER e AVRITZER, 2004). No caso dos conselhos de política, em especial dos conselhos de saúde, é possível apontar algo semelhante em relação à sua implementação em São Paulo. Ela é dependente da existência de uma forte organização da sociedade civil na cidade (SADER, 1988; COELHO, 2004; AVRITZER, 2009, no prelo), assim como da vontade política do governante. No entanto, uma variável importante diferencia os conselhos de saúde do OP: a existência de sanções no caso de não implementação. Se ainda levamos em conta uma terceira experiência, a dos Planos Diretores Municipais (PDM), percebemos uma terceira combinação entre as três variáveis: os PDMs são a instituição participativa menos dependente da vontade do governo, ainda que dependam do nível de organização da sociedade civil, tal como mostram as experiências recentes de Belo Horizonte, São Paulo e Salvador (MILANI, 2005; AVRITZER, 2009, no prelo).

\footnotetext{
1 Existem diversos trabalhos mostrando o papel do governo na constituição do orçamento participativo. Abers e Santos se inclinam para uma posição que ressalta mais fortemente a iniciativa do Estado, ao passo que Avritzer e Baiochi enfatizam aspectos da organização da sociedade civil. Vide Santos, 1998; Abers, 2000; Avritzer, 2002 e Baiochi, 2005.

2 Evidentemente que é possível, do ponto de vista heurístico, supor uma instituição de partilha de poder não determinada legalmente, ainda que a participação dos atores estatais esteja amplamente determinada por motivações políticas e ideológicas.
} 
Portanto, é possível notar que as instituições participativas variam na sua capacidade de democratizar o governo. As principais variações estão relacionadas ao contexto de organização da sociedade civil $^{3}$ e à presença de atores políticos capazes de apoiar unificadamente processos participativos. Nesta última categoria, vale a pena observar variações no próprio apoio oferecido pelo Partido dos Trabalhadores a processos participativos. Na medida em que passamos a trabalhar com o contexto como variável relevante passamos, ao mesmo tempo, a relativizar o papel do desenho institucional tomado separadamente para pensar as instituições participativas. Diferentemente de Fung e Wright que atribuem ao desenho institucional a capacidade de gerar êxito nos processos participativos e propõem a repetição de desenhos independentemente de contexto (FUNG e WRIGHT, 2003), neste artigo, propomos uma outra categoria que denominamos de desenho participativo interativo. Neste caso, o sucesso dos processos participativos está relacionado não ao desenho institucional e sim à maneira como se articulam desenho institucional, organização da sociedade civil e vontade política de implementar desenhos participativos.

Nas próximas três seções deste artigo, discutimos os desenhos de baixo para cima, os desenhos de partilha de poder e os desenhos de ratificação em quatro contextos diferenciados: as cidades de São Paulo, Porto Alegre, Belo Horizonte e Salvador. Diferenciamos os casos de participação nas quatro cidades relacionandoos aos diferentes desenhos institucionais participativos implantados em cada uma delas.

\section{Orçamento participativo, organização da sociedade e sistema político no Brasil}

O orçamento participativo é uma das instituições participativas mais conhecidas internacionalmente devido ao sucesso da experiência em Porto Alegre vigente entre 1990 e 20054. O surgimento do orçamento participativo está relacionado a condições muito particulares da cidade de Porto Alegre, tais como a existência de uma forte tradição de organização da sociedade civil, em particular dos movimentos comunitários ainda nos anos cinqüenta do século XX (BAIERLE, 1998; BAQUERO, 2000; AVRITZER, 2006). Porto Alegre contou também com uma

\footnotetext{
3 Vale a pena mencionar aqui que, tanto pela sua dimensão quanto pelas variações culturais, o Brasil tem padrões diferenciados de organização da sociedade civil. Ainda nos anos cinqüenta, a cidade de Porto Alegre desenvolveu um associativismo comunitário bastante forte, ao passo que as principais capitais do sudeste apenas constituíram um associativismo comunitário forte durante a democratização. Já no caso das capitais do nordeste, Salvador continua tendo um associativismo comunitário fraco (AVRITZER, 2007).

${ }^{4}$ A partir de 2006 o orçamento participativo de Porto alegre se transformou no processo de participação solidária (vide Porto Alegre, 2006).
} 
tradição política diferenciada em relação a outras regiões do Brasil, sendo a única cidade na qual o PTB, Partido Trabalhista Brasileiro, ganhou eleições continuamente entre 1946 e 1964 (AVRITZER, 2006). Esta tradição fez com que a conjuntura política da cidade de Porto Alegre fosse diferente daquela vigente em outras cidades brasileiras no momento imediatamente posterior a redemocratização brasileira em 1985. Enquanto em todas as principais cidades do sul e sudeste do Brasil, em particular, Rio de Janeiro, São Paulo e Belo Horizonte houve um embate entre partidos de direita e partidos de esquerda, em Porto Alegre houve uma disputa no interior do campo da própria esquerda, com o PDT, Partido Democrático Trabalhista ganhando a primeira eleição posterior à democratização em 1986. Foi neste momento que as alternativas em torno de políticas participativas se colocaram na cidade, a partir da configuração específica da sociedade civil e da sociedade política na cidade.

Ao vencer as eleições para prefeito de 1986, Alceu Collares, do PDT, procurou os movimentos comunitários da cidade e propôs uma forma de participação no orçamento chamada de "fiscal de bairro". Ao mesmo tempo, a UAMPA (União das Associações de Moradores de Porto Alegre) constituída no final do período autoritário já havia se posicionado em seu congresso em 1986 a favor de formas de participação no orçamento. É desta dupla interseção entre sociedade civil e sociedade política que surge a idéia da participação no orçamento. O PT, Partido dos Trabalhadores, apresenta, então, a idéia de conselhos populares e concorre contra o PDT nas eleições de 1988, vencendo-as. Assim, uma interseção muito particular entre sociedade civil e sociedade política se manifesta em Porto Alegre no final dos anos oitenta. Partidos de esquerda disputam o poder na cidade propondo formas diferenciadas de participação. Ao mesmo tempo, uma sociedade civil organizada tenta radicalizar estas formas no nível local, já que a UAMPA desde 1986 propunha a participação da população nas regiões (UAMPA, 1986). Nos primeiros trinta dias do governo Olívio Dutra, a idéia de um orçamento participativo irá se consolidar mais uma vez, na interseção entre sociedade civil e sociedade política. A vinda de importantes lideranças comunitárias para a prefeitura e sua integração à CRC (Coordenação de Relações com a Comunidade) viabilizam a idéia de um orçamento participativo a partir das regiões. Como é possível observar na Tabela 1, a participação inicial varia e é completamente dependente da organização prévia das regiões. 
Tabela 1. Participação em Porto Alegre por regiões selecionadas

\begin{tabular}{|c|c|c|c|c|c|c|}
\hline & Região & 1990 & 1992 & 1994 & 1996 & 1998 \\
\hline \multirow{4}{*}{$\begin{array}{l}\text { Regiões } \\
\text { com } \\
\text { tradição } \\
\text { associativa }\end{array}$} & Leste & 152 & 510 & 339 & 623 & 710 \\
\hline & Lomba & 64 & 569 & 575 & 973 & 638 \\
\hline & Partenon & 75 & 1096 & 661 & 809 & 805 \\
\hline & Cruzeiro & 181 & 297 & 494 & 649 & 604 \\
\hline \multirow{4}{*}{$\begin{array}{l}\text { Regiões } \\
\text { sem } \\
\text { tradição } \\
\text { associativa }\end{array}$} & Navegantes & 15 & 165 & 135 & 495 & 624 \\
\hline & Nordeste & 33 & 276 & 350 & 682 & 906 \\
\hline & Restinga & 36 & 369 & 1096 & 763 & 1348 \\
\hline & Centro-Sul & 101 & 591 & 352 & 1513 & 1461 \\
\hline
\end{tabular}

Fonte: Prefeitura Municipal de Porto Alegre, CRC (Porto Alegre, 2000).

Não é difícil ver em operação os elementos que fizeram do OP de Porto Alegre um caso exitoso de participação "de baixo para cima": a presença de uma sociedade civil forte e a existência uma sociedade política à esquerda do espectro político. A associação entre ambas gerou o OP e foi capaz de sustentá-lo durante os primeiros anos quando a participação não era tão alta. Quando nos voltamos para os dois outros casos de OP, o de Belo Horizonte e o de São Paulo, podemos imediatamente perceber uma variação nestes fatores. O OP de Belo Horizonte não representou uma experiência muito diferente em relação à de Porto Alegre. A formação de movimentos comunitários fortes em Belo Horizonte é muito posterior à sua formação em Porto Alegre e ocorreu apenas no começo da redemocratização brasileira a partir de metade dos anos 70 (AVRITZER, 2000). Já o Partido dos Trabalhadores tem em Minas Gerais um das suas quatro principais bases iniciais (KECK,1992). No entanto, o PT belo horizontino nunca foi tão homogeneamente 
participativo quanto o PT porto-alegrense. Grupos no interior do PT de Belo Horizonte manifestaram um certo ceticismo em relação ao OP que se expressou no desenho institucional mais fraco do OP na cidade. Inicialmente, não havia um Conselho do Orçamento Participativo em Belo Horizonte (AVRITZER, 2002). Ainda assim, o OP foi amplamente exitoso em Belo Horizonte no que diz respeito tanto à participação quanto aos seus aspectos distributivos (PIRES, 2007). O caso do OP mais interessante de ser analisado, por constituir um excelente exemplo das limitações existentes para a implantação do orçamento participativo, é o da cidade de São Paulo.

São Paulo é uma das cidades nas quais a sociedade civil mais fortemente se re-organizou no início da redemocratização (SADER, 1988). Diversos movimentos que se tornaram importantes nacionalmente tiveram a sua origem na cidade, entre os quais o movimento popular de saúde (SADER, 1988; JACOBI, 1995; COELHO, 2004; AVRITZER, 2009, no prelo) e o movimento nacional pela reforma urbana (SAULE, 2005; FERNANDES, 2005). No entanto, a sociedade civil paulistana desde o início da redemocratização expressou uma desigualdade regional: ela sempre foi mais forte nas zonas leste e oeste da cidade do que na zona sul, fenômeno este ligado às características da ação da igreja católica em São Paulo (DOIMO, 2004). Este fenômeno se acentuou com a divisão da arquidiocese da cidade pelo Papa João Paulo II no começo dos anos oitenta consolidando o fenômeno da regionalização da sociedade civil. Ao mesmo tempo, São Paulo, o berço do Partido dos Trabalhadores, sempre foi uma cidade no qual o partido teve maior influência de um grupo não participativo ${ }^{5}$ do que de grupos participativos. Entre os três grupos que deram origem ao PT (MENEGUELLO, 1989), novo sindicalismo, nova esquerda e catolicismo de base (CASANOVA, 1994), apenas este último tentou implantar políticas participativas e sua presença sempre foi desigual na cidade. Como conseqüência deste processo, no caso da cidade de São Paulo, a sociedade civil não teve, historicamente, força para demandar políticas participativas e nem a sociedade política teve empatia com a sociedade civil para transformar uma política participativa em uma política de governo.

O PT ocupou por duas vezes a prefeitura da cidade de São Paulo e, em ambas, enfrentou insucessos muito fortes na implementação de políticas participativas. A primeira experiência do PT na prefeitura de São Paulo, que foi simultânea à eleição de Olívio Dutra para a prefeitura de Porto Alegre m 1988, foi marcada por profundas divisões internas no interior do partido (COUTO,1994). A política participativa, que chegou a receber o nome de orçamento participativo naquele período, não foi capaz de ser aprovada na câmara municipal e de ser

\footnotetext{
${ }^{5}$ Este processo está diretamente ligado ao surgimento e consolidação da liderança de José Dirceu no PT a partir de meados dos anos oitenta. José Dirceu conquista a secretaria geral do PT. em 1986 e, a partir daí, fortaleceu grupos da nova esquerda que tem uma visão bastante cética dos processos participativos.
} 
implementada (SINGER, 1993). A volta do PT à prefeitura de São Paulo no ano 2000 colocou novamente a questão da centralidade das políticas participativas e do OP. Marta Suplicy foi eleita prefeita com 38\% dos votos no primeiro turno, mostrando uma evolução problemática dos votos do PT na capital paulista em comparação com Belo Horizonte e Porto Alegre, tal como mostra a Tabela 2. A necessidade do PT de aumentar o percentual de votos na cidade e a desconfiança de setores importantes da administração Marta Suplicy acerca da adequação das políticas participativas em relação a tal objetivo levaram à decisão de implantar o OP como uma entre diversas políticas públicas setoriais. Assim, a partir de 2002 passou a haver OP na cidade de São Paulo.

Tabela 2. Votos para prefeito em Porto Alegre, Belo Horizonte e São Paulo (\%)

\begin{tabular}{|l|l|l|l||l|l||}
\hline & 1988 & 1992 & 1996 & 2000 & 2004 \\
\hline São Paulo & $33,0 \%$ & $30,68 \%$ & $24,51 \%$ & $38 \%$ & $35,8 \%$ \\
\hline \hline Belo Horizonte & $24,0 \%$ & $36,91 \%$ & $22 \%$ & $46 \%$ & $68,4 \%$ \\
\hline Porto Alegre & $34,34 \%$ & $40,76 \%$ & $55,0 \%$ & $48,7 \%$ & $37 \%$ \\
\hline \hline
\end{tabular}

Fonte: (TRE).

O orçamento participativo implantado na cidade de São Paulo teve as seguintes características: 1) seguiu uma lógica organizativa muito semelhante a do OP de Porto Alegre com a realização de assembléias regionais e a eleição de um conselho; 2) OP teve baixa centralidade política na administração Marta Suplicy, tendo sido delegado a um dos grupos de esquerda mais especializados na participação política, mas relativamente isolado na administração; 3) diferentemente do OP de Porto Alegre, o de São Paulo não foi a principal forma de distribuição de bens públicos para a população pobre da cidade. Junto com o OP, operou um programa de bolsas para a população carente, que recebeu uma quantidade muito superior de recursos. Ainda houve uma terceira política pública na administração Marta Suplicy, o programa de Centros Integrados de Educação. 
Deste modo, é possível perceber que a implantação do OP na cidade de São Paulo teve fortes constrangimentos políticos. Os programas sociais mais importantes da prefeitura tiveram recursos muito superiores ao OP e não tiveram qualquer componente participativo. Já o OP funcionou adequadamente e com poucos recursos apenas em regiões que já tinham tradição de participação. Ao mesmo tempo, devido a constrangimentos eleitorais, a administração Marta Suplicy realizou amplas coalizões para a indicação de administradores regionais. Alguns destes administradores estavam absolutamente fora do campo participativo e prejudicaram a implantação de decisões do OP nas suas regiões. Assim, ao compararmos a implementação do OP em São Paulo com a sua implementação em Porto Alegre e Belo Horizonte podemos dizer que, em São Paulo, o OP não encontrou o amparo necessário na administração devido à falta de centralidade das políticas participativas na agenda do grupo do PT que esteve no centro da administração Marta Suplicy. Podemos observar que a capacidade de implementar políticas participativas é bastante baixa nos casos de OP nos quais falta a vontade política do governante. Ademais, ainda em São Paulo, a sociedade civil não chegou a ser forte o suficiente para transformar o OP na principal política distributiva na cidade. Neste sentido, se o OP é uma política participativa fortemente democratizante, ele também é uma política participativa fortemente dependente da vontade do governante. O que analisamos a seguir é a implantação dos conselhos de saúde e dos planos diretores municipais nas três cidades.

\section{Conselhos de Saúde e partilha de poder: uma comparação com o orçamento participativo}

O orçamento participativo não é a única política participativa que despontou no Brasil democrático. Os conselhos de saúde, que têm uma origem diferente do $\mathrm{OP}$, também surgiram no mesmo período e estão hoje presentes em mais de 5.000 municípios no Brasil. A origem dos conselhos de saúde está ligada a dois movimentos sociais importantes da redemocratização brasileira: de um lado, o movimento sanitarista que envolveu médicos, enfermeiros e outros profissionais de saúde e se tornou forte no final dos anos 70 nas universidades e alguns outros setores selecionados da área de saúde como a Fundação Oswaldo Cruz (ESCOREL, 2002) e,de outro lado, o chamado movimento popular da saúde, que teve a sua origem na zona leste da cidade de São Paulo e envolveu mães e outros usuários da saúde cujo objetivo principal era controlar a qualidade dos serviços de saúde na região leste da cidade (SADER, 1988; JACOBI, 1994). Cada um destes grupos tinha um tipo de reivindicação em relação à participação social: no caso do movimento popular de saúde, a reivindicação era o controle e, eventualmente, a autonomia da 
sociedade civil no processo de decisão sobre os serviços de saúde municipal, proposta esta que foi abandonada no final da primeira metade dos anos oitenta. Do lado dos médicos sanitaristas, a ênfase foi posta na medicina preventiva e na reorganização do papel do Estado no sistema de saúde do país.

O movimento de saúde teve dois momentos cruciais nos anos oitenta: o primeiro deles foi a assim chamada "VIII Conferência Nacional de Saúde" ocorrida em Brasília, em 1986, e propôs a extinção dos "Institutos de Previdência", que eram a expressão maior da vigência de um direito segmentado à saúde (GERSCHMAN, 1995, p.78). No entanto, do ponto de vista da participação, o elemento que sobressai na VIII Conferência Nacional de Saúde é a combinação entre a reivindicação de um Estado mais ativista por parte do movimento sanitarista e de uma forma popular de controle público por parte dos movimentos populares. Esta combinação gerou a instituição participativa no conselho como forma geral da participação na saúde (AVRITZER, 2009, no prelo). A proposta de um sistema unificado de saúde, descentralizado e com participação popular foi apresentada sob a forma de uma emenda popular durante a Assembléia Nacional Constituinte e aprovada com algumas modificações propostas pelos setores conservadores ${ }^{6}$.

A aprovação do capítulo 186 da Constituinte sobre a saúde foi uma enorme vitória dos movimentos populares da sociedade civil naquele período. No entanto, esta vitória não anulou a necessidade de outras batalhas, entre as quais deve ser mencionada a luta pela incorporação dos conselhos na legislação ordinária que se seguiu a Constituinte. A LOS - Lei Orgânica da Saúde - foi proposta em 1990, durante o primeiro ano de governo do ex-presidente Collor de Mello, que na primeira versão vetou integralmente todos os institutos da participação popular. Apenas em dezembro de 1990 surgiu a lei 8.142 que instituiu os conselhos na área de saúde. Os conselhos são, assim, o resultado da convergência de concepção de dois movimentos importantes, o sanitarista e o popular da saúde. Os conselhos, na maneira como eles introduziram a questão da partilha do poder em uma instituição híbrida, são também o resultado de diferentes negociações após o processo constituinte. Um dos seus elementos mais importantes é a associação entre a falta da participação e sanção, expressa na suspensão da transferência de recursos públicos federais para os municípios que não praticarem a participação popular na saúde. Com o objetivo de avaliar a efetividade deliberativa dos conselhos, analisamos muito brevemente os casos de Belo Horizonte e de Porto Alegre (AVRITZER, 2009, no prelo) e mais detalhadamente os casos de São Paulo e Salvador.

\footnotetext{
6 A principal agenda dos setores conservadores na área de saúde durante a assembléia nacional constituinte foi a proposta de combinar serviços privados com um sistema estatal de saúde. Vide Pereira, 2002.
} 
Os casos dos conselhos de saúde de Porto Alegre e Belo Horizonte são interessantes, mas não se diferenciam completamente dos casos de OP nas duas cidades. O Conselho de Saúde de Belo Horizonte está entre os mais antigos do país, assim como o movimento de saúde na cidade. O Conselho de Saúde de Belo Horizonte foi criado pela lei municipal 5.903 de 1991, pouco depois da legislação nacional sobre o assunto. O episódio mais interessante envolvendo este conselho de saúde diz respeito à eleição de um membro da sociedade civil para a presidência do conselho. No caso do conselho da cidade de Porto Alegre, ele foi criado em 1992 e sua característica mais importante é não considerar prestadores de serviços como parte da sociedade civil. Ainda que os dois conselhos tenham inovado em alguns aspectos referentes ao desenho institucional, o elemento que mais chama a atenção é que eles reproduzem características exitosas da participação no orçamento participativo (CORTES, 2002; REOS, 2005; AVRITZER et al, 2005; (AVRITZER, 2009, no prelo). Assim, é possível afirmar que nos casos em que o desenho institucional "de baixo para cima" é exitoso, o desenho de partilha também é. No entanto, o que interessa aqui são justamente os casos nos quais o desenho de partilha é implantado na ausência de uma sociedade civil forte ou contra a vontade da sociedade política.

A organização dos conselhos de saúde na cidade de São Paulo é um caso instrutivo para analisar a diferença entre os tipos de desenho institucional participativo. O conselho municipal de saúde de São Paulo foi criado pela prefeita Luiza Erundina em junho de 1989. Portanto, antes da própria regulamentação da lei municipal destacada anteriormente. O conselho de saúde da cidade de São Paulo tem uma composição paritária através da qual tanto os representantes das regiões quanto as associações da sociedade civil ligadas às questões de saúde adquirem representação no conselho. O conselho possui atribuições normativas e deliberativas. Entre as atribuições deliberativas destacam-se a aprovação do plano municipal de saúde.

O primeiro momento de implantação do conselho de saúde durante a administração Luiza Erundina do PT não implicou em conflitos importantes entre sociedade civil e Estado. Estes conflitos apareceram nas gestões posteriores, ligadas ao "malufismo" (1993-1996 e 1997-2000). Nestes momentos, a política municipal de saúde sofreu uma inflexão conservadora marcada por dois elementos principais: o primeiro deles foi a tentativa de privatização dos serviços municipais de saúde através da criação de cooperativas médicas e da extensão da rede de serviços privados de saúde (GOHN e ELIAS, 1997). Essa política sofreu a oposição ativa do conselho municipal de saúde e resultou na aplicação da sanção prevista em lei: a suspensão dos repasses do governo federal para a cidade de São Paulo; em segundo lugar, como conseqüência dos conflitos anteriormente mencionados, houve uma forte tentativa de intervenção por parte da administração municipal na composição 
da representação da sociedade civil no conselho de saúde. Esta envolveu a inclusão de provedores de serviços privados na representação da sociedade civil e a tentativa de criar associações de saúde com o objetivo de preencher as quotas da sociedade civil no conselho. Foi também tentada a mudança da legislação através de dois novos decretos (decretos $n^{\circ} 37.330$ e 38.000), ambos modificando a estrutura de representação da sociedade civil no conselho (São Paulo, 07/07/2000). A resposta dos representantes da sociedade civil foi reelaborar o estatuto do conselho de forma a qualificar melhor o conceito de representação da sociedade civil. De acordo com o sexto parágrafo do Decreto n³8.576 de 1999 “ ... entende-se por Movimento Popular de Saúde (MPS) a organização da sociedade civil, constituída, dotada de ampla publicidade, com existência mínima de 12 (doze) meses anteriores à publicação deste decreto, cujos objetivos constitutivos e prática corrente têm na saúde e no usuário sua ênfase fundamental e, verificada a sua estrutura organizacional, possuam documentação comprobatória de existência e representatividade da área, de forma a possibilitar sua habilitação para se fazer representar no Conselho Municipal de Saúde." Assim, nos casos em que as organizações da sociedade civil são fortes, é possível, através da sanção estabelecida pela lei e pela formas de organização dos movimentos populares em questão, resistir a uma tentativa do governo de retirar poder da instância participativa. Dessa forma, os desenhos de partilha se diferenciam dos desenhos de participação "de baixo para cima" devido a sua maior independência do sistema político.

Vale a pena ainda mencionar rapidamente o caso do conselho de saúde da cidade de Salvador. Este conselho foi criado em 1991 em virtude da exigência colocada pela lei $n^{\circ} 8142$. O primeiro contraste em relação a outros casos de conselho analisados diz respeito à sua composição. Diferentemente do padrão das três cidades antes mencionadas, o conselho de saúde de Salvador tem uma concepção bastante particular da representação da sociedade civil: esta é constituída pela Arquidiocese da cidade, pela Associação Comercial e por algumas associações étnicas ligadas à raça negra. Essa composição afeta a capacidade da sociedade civil de se expressar no conselho, assim como a capacidade deliberativa do conselho (AVRITZER, 2007). Em uma pesquisa comparativa sobre a capacidade deliberativa dos conselhos de saúde, o conselho de Salvador se destacou como tendo como principal deliberação o envio de documentos ao governo. Pode-se, então, dizer que este é um caso diferenciado no qual a fraqueza da sociedade civil e a hostilidade do sistema político levam a um conselho inefetivo. O que diferencia o caso de Salvador do caso de São Paulo é a fraqueza da sociedade civil, já que, no que diz respeito à hostilidade da sociedade política não há grandes diferenças entre 
o malufismo e o carlismo ${ }^{7}$. Em seguida, analisamos um terceiro caso de desenho participativo, o das experiências de ratificação pública.

\section{Desenhos participativos e ratificação pública: uma análise comparada}

A análise comparada dos desenhos participativos envolve um terceiro caso denominado de ratificação pública, que difere tanto dos desenhos "de baixo para cima" quanto dos desenhos de partilha de poder. No caso dos primeiros, a grande diferença com o processo de ratificação pública é que eles não iniciam o processo de deliberação política, mas, pelo contrário, finalizam um processo já iniciado no âmbito do próprio Estado. Em relação ao processo de partilha de poder, os desenhos de ratificação pública variam no que se refere à maneira como Estado e sociedade civil se relacionam: no caso dos desenhos de ratificação pública eles envolvem mais atores sociais na ratificação e sua relação é com uma decisão tomada anteriormente pelo Estado. A questão que se coloca é quais são as conseqüências deste desenho e em qual contexto ele se mostra mais útil para fomentar processos participativos. O caso dos planos diretores municipais permite esta comparação.

Os Planos Diretores Municipais são a terceira forma de participação surgida no Brasil democrático. Sua origem se assenta na formação do MNRU, Movimento Nacional pela Reforma Urbana. O MNRU se formou ainda durante a primeira experiência democrática brasileira quando ocorreu uma primeira reunião nacional pela reforma urbana em 1963 no Hotel Quitandinha em Petrópolis. O movimento foi interrompido pelo golpe militar de 1964 e só voltou a se formar em 1982 no contexto da redemocratização (SILVA, 1991). Na sua composição inicial o MNRU foi o primeiro movimento nacional da sociedade civil brasileira e expressou uma ampla aliança formada pelas associações de bairro, sindicatos, ONG's e associações profissionais, tal como mostra a Tabela 3:

\footnotetext{
7 Referências aos políticos Paulo Salim Maluf (São Paulo) e Antônio Carlos Magalhães (Salvador).
} 
AVRITZER, L. Instituições participativas e desenho institucional...

\section{Tabela 3. Composição do MNRU (Movimento Nacional pela Reforma Urbana)}

\begin{tabular}{||l||l||}
\hline Movimentos populares & $\begin{array}{l}\text { MDF - Movimento de Defesa dos } \\
\text { Favelados }\end{array}$ \\
\hline \hline Associações de bairro & FAMERJ \\
\hline ONGs & FASE, POLIS \\
\hline \hline Sindicatos & $\begin{array}{l}\text { Federação Nacional dos Engenheiros; } \\
\text { Federação Nacional dos Arquitetos }\end{array}$ \\
\hline Associação profissional & ANSUR \\
\hline
\end{tabular}

Fonte: (Brasil,2004)

O MNRU apresentou à Assembléia Nacional Constituinte, tal como fez o movimento de saúde, uma proposta de emenda popular. Essa proposta envolveu os seguintes elementos: direito à cidade; participação popular nas decisões urbanas; direito de preempção (direito do estado de se antecipar ao desenvolvimento urbano reservando áreas nas cidades); imposto urbano progressivo e outorga onerosa (legalização das áreas públicas de até 250 metros ocupadas pela população). Durante a Assembléia Nacional Constituinte, a maior parte destas reivindicações foram incluídas no texto constitucional, mas surgiu a proposta de integrá-las em um plano diretor municipal (SAULE, 1995), proposta dos setores conservadores visando retardar a implementação da reforma urbana. Com a necessidade de produzir legislação ordinária regulamentando o capítulo da reforma urbana, teve início um processo de disputa e negociação no legislativo que durou quase 14 anos (AVRITZER, 2009, no prelo). No decorrer deste processo, o MNRU tornou-se FNRU e desenvolveu uma estrutura de lobby da sociedade civil que permitiu, ao final de 14 anos de tramitação legislativa, a aprovação do Estatuto da Cidade. O estatuto da cidade exige que todas as cidades brasileiras com mais de 20.000 habitantes tenham planos diretores municipais aprovados em audiências públicas. Praticamente todas as capitais brasileiras já tiveram os seus planos diretores municipais aprovados. Entre elas, vale a pena ressaltar os casos de São Paulo e

\footnotetext{
8 Não iremos aqui analisar os casos de Porto Alegre e Belo Horizonte que se inserem no mesmo marco teórico anterior, isso é, mostram que em contextos nos quais as instituições de baixo para cima são exitosas todas as outras instituições participativas também o são.
} 
Salvador, uma vez que parecem lançar mais luz sobre diferenças de contexto no sucesso das instituições participativas.

O plano diretor da cidade de São Paulo foi uma das prioridades da gestão da prefeita Marta Suplicy. O PDM de São Paulo foi elaborado durante o primeiro ano de governo e enviado à câmara dos vereadores em maio de 2002. O relator na câmara foi Nabil Bonduki, um veterano do movimento da reforma urbana e um conhecido professor de planejamento urbano da USP. O fato de o relator ter uma forte identidade com o MNRU não deve ser menosprezado. Ainda assim, o PDM de São Paulo sofreu forte oposição na câmara e na justiça, especialmente no que diz respeito às mudanças de zoneamento e ao aumento de zonas exclusivamente residenciais na cidade. No processo de aprovação do plano foram conduzidas 26 audiências públicas e foram realizadas 15 reuniões com Ongs. No caso do PDM da cidade de São Paulo, parece bastante claro que havia uma grande convergência entre sociedade civil e governo. No entanto, a reação ao plano apareceu de setores conservadores cujos interesses estavam sendo diretamente afetados pela mudança em certos zoneamentos. Estes setores foram à justiça com duas grandes reclamações: a primeira delas diz respeito a informações incompletas em relação às mudanças de zoneamento; a segunda diz respeito a não aceitação pela cidade de representantes dos proprietários, principalmente advogados de associações de proprietários e imobiliárias na cidade. A justiça acatou ambos argumentos obrigando a prefeitura a refazer as audiências públicas (FSP,13/11/2003). Ao final deste processo o PMD de São Paulo foi aprovado com um elevado numero de emendas pontuais de vereadores que mudavam pequenas configurações do zoneamento na tentativa de atender a interesses pontuais. O caso do PMD de São Paulo mostra uma sociedade civil dividida e uma sociedade política que necessita da normatização da participação popular para torná-la eficaz. Vale a pena contrastar o caso de São Paulo com o de Salvador para entender a variação de resultados em desenhos com sanção normativa.

Analisar o plano diretor municipal de Salvador é importante para entender o funcionamento do desenho participativo de ratificação. Salvador é conhecida como uma das cidades brasileiras com uma fraca presença da sociedade civil nas políticas públicas ${ }^{9}$. Salvador foi governada até 2004 por uma corrente política conservadora e anti-participativa denomidada carlismo. No caso das instituições participativas ligadas à saúde, Salvador é o caso de não democratização das políticas de saúde devido a uma política de nomeação de grupos econômicos locais e grupos religiosos para a representação da sociedade civil (AVRITZER, 2007). Salvador foi das poucas grandes cidades brasileiras a ter o seu plano diretor municipal anulado

\footnotetext{
9 Vale a pena, no entanto, qualificar este dado. O número de associações civis existentes na cidade de Salvador é bastante alto (2.500 associações). O número de associações civis ligadas às políticas públicas é que é baixo. Vide Avritzer, 2007.
} 
judicialmente. A partir da aprovação do Estatuto da Cidade e da decisão de elaborar um plano diretor municipal, a cidade contratou uma consultoria privada para a elaboração de uma proposta de plano. Associações da sociedade civil ligadas à questão da reforma urbana não foram sequer informadas da existência de uma consultoria encarregada da elaboração de uma proposta de plano diretor municipal (MILANI, 2005). As audiências públicas para o plano foram mantidas no mínino exigido pela lei e com baixíssima presença. Nenhuma audiência foi divulgada por outro veículo de comunicação que não fosse o Diário Oficial do município. No final, foram realizadas apenas duas audiências públicas no ano de 2003 com baixíssima presença da população e de associações civis. Foi neste contexto que "a Federação de Associações de Bairros de Salvador (FABS), alguns movimentos ambientalistas e a Ordem dos Advogados do Brasil (seção Bahia) formularam representação à Promotoria de Meio Ambiente, antes da segunda audiência pública, solicitando ao Ministério Público Estadual que viabilizasse a discussão do PDDU (Plano Diretor de Desenvolvimento Urbano) junto às comunidades de Salvador, de acordo com o que determina o Estatuto da Cidade."(MILANI, 2005). No entanto, a prefeitura de Salvador enviou a proposta de Plano Diretor de Desenvolvimento Urbano à Câmara Municipal antes que este debate se viabilizasse e obrigou o ministério público da cidade a entrar com ação na qual pediu a declaração de nulidade do plano e o julgamento do prefeito Imbassaí por improbidade administrativa. O plano foi embargado pela justiça e foi retomado pelo prefeito seguinte que organizou uma audiência pública com mais de 800 pessoas entre ativistas e representantes de ONG's. Assim, o caso de Salvador é bastante interessante inclusive quando comparado com outros casos de participação na mesma cidade que, pelo menos até 2004, foi a capital brasileira que menos aderiu às novas formas de participação. Este é também interessante pela utilização do desenho institucional de ratificação para impedir um governo conservador de implantar a sua política urbana sem antes negociá-la com a sociedade civil. Ele mostra que, em contextos completamente hostis à participação, o desenho mais capaz de anular políticas particularistas é o desenho de ratificação pública. Entre os três tipos de desenhos participativos discutidos neste artigo apenas este foi capaz de operar em uma cidade fortemente anti-participativa.

\section{Conclusão}

Os três tipos de casos abordados acima nos permitem tratar de algumas características adicionais dos desenhos participativos. Em primeiro lugar, deve ser ressaltado o problema da diferença quanto à efetividade deliberativa dos desenhos "de baixo para cima", dos desenhos de partilha e dos desenhos de ratificação. Não 
existem dúvidas de que os desenhos de baixo para cima como o OP são os mais fortemente democratizantes e distributivos. Os casos dos desenhos de partilhas são os mais fortemente democratizantes nos caso de oposição à participação por parte da sociedade política. Os casos de ratificação são os casos mais efetivos quando há necessidade da sanção por parte do judiciário e do ministério público para a manutenção das formas de participação previstas em lei. Neste sentido, podemos pensar em uma tipologia inicial dos desenhos participativos que se organizaria em dois eixos: a capacidade de aprofundar práticas democráticas e a capacidade de tornar o desenho efetivo na determinação da política pública em questão. Ao adotarmos uma tipologia com estes elementos podemos claramente diferenciar desenhos participativos, tal como mostra a Tabela 4. Em primeiro lugar, podemos observar que o OP é o desenho participativo mais democratizante, devido à sua capacidade de alterar a relação entre o Estado e a sociedade, incluindo a população na deliberação sobre prioridades orçamentárias. Mas, foi possível observar também que o OP é o desenho participativo mais vulnerável à vontade da sociedade política.

\section{Tabela 4. Tipologia sobre a efetividade dos desenhos participativos}

\begin{tabular}{||c||c|c||c|}
\hline $\begin{array}{c}\text { Tipo de } \\
\text { desenho }\end{array}$ & $\begin{array}{c}\text { Orçamento Participativo } \\
\text { Desenho de baixo para } \\
\text { cima }\end{array}$ & $\begin{array}{c}\text { Conselho de políticas } \\
\text { Desenho de partilha }\end{array}$ & $\begin{array}{c}\text { Plano diretor } \\
\text { municipal }\end{array}$ \\
\hline $\begin{array}{c}\text { Capacidade } \\
\text { democratizante }\end{array}$ & Alta & Média & Baixa \\
\hline \hline $\begin{array}{c}\text { Efetividade/ } \\
\text { Dependência } \\
\text { do } \\
\begin{array}{c}\text { Sistema } \\
\text { político }\end{array}\end{array}$ & Alta & Maixa \\
\hline
\end{tabular}

Esta tipologia da participação permite analisar os desenhos de partilha do poder cuja característica principal é uma dependência menor do sistema político do que a dependência nos desenhos "de cima para baixo". Em uma situação na qual a sociedade civil é forte, os desenhos de partilha permitem que esta desafie a decisão da sociedade política de não implantar processos participativos, tal como foi o caso na área de saúde na cidade de São Paulo. O caso do conselho de saúde na cidade 
de São Paulo mostra também o papel da sanção e a utilização que a sociedade civil pode fazer da sanção no caso da não implementação da participação. Mas o caso mais instrutivo de desenho participativo é o de Salvador, um caso em que a participação existente em lei foi capaz de bloquear ações de uma sociedade política anti-participativa. O que torna o caso de Salvador mais interessante é a debilidade da sociedade civil, pois mostra a operação do instrumento de sanção em um caso em que a sociedade civil é débil e o sistema político anti-participativo. Esta tipologia de formas de desenho participativo chama atenção para a importância da variação do contexto na efetividade da participação. Neste momento, no qual um certo entusiasmo pouco crítico com as experiências de participação parece estar sendo superado por uma análise mais criteriosa, tudo parece indicar que a natureza do desenho participativo passará a ter uma enorme influência no sucesso das experiências participativas e que a escolha do desenho adequado será uma das variáveis fundamentais para a continuidade destas experiências no futuro.

\section{Referências bibliográficas}

ABERS, R. N. Inventing local democracy: grassroots politics in Brazil. Boulder: Lynne Rienner Publishers, 2000.

ARCHON, F. and WRIGHT, E. O. (eds.). Deepening democracy: institutional innovations in empowered participatory governance (Real Utopias Project). London:Verso, 2003.

AVRITZER, L. Democratization and changes in the pattern of association in Brazil. Journal of Interamerican Studies and World Affairs, vol. 42, n. 3, 2000.

University Press, 2002a.

Democracy and the public space in Latin America. Princeton: Princeton

Orçamento Participativo: as experiências de Porto Alegre e Belo

Horizonte. In: DAGNINO, E. (ed.). Sociedade civil e espaços públicos no Brasil. São Paulo: Paz e Terra, 2002b.

Research, 2006. "New public spheres in Brazil". International Journal of Urban Regional

2007. A participação social no nordeste. Belo Horizonte: Editora da UFMG, . Participatory Institutions in Democratic Brazil. Baltimore: John Hopkins University Press, 2009 no prelo. 
AVRITZER, L. et al. Reiventando os mecanismos de inclusão e controle social nos conselhos de saúde, 2005. Disponível em: <http://www.democraciaparticipativa.org/pesquisas> Acesso em: 10 maio. 2006.

BAIERLE, S. G. The explosion of experience: the emergence of a new ethical-political principle in popular movements in Porto Alegre, Brazil. In: ALVAREZ, S. E.; DAGNINO, E.; ESCOBAR, A. (eds.). Cultures Of Politics/Politics Of Cultures: Re-Visioning Latin American Social Movements. 1a. ed. Boulder, Colorado, EUA: Westview Press, 1988.

BAIOCCHI, G. Participation, activism and politics. In: FUNG, A. and WRIGHT, E. Deepening democracy: institutional innovations in empowered participatory governance (Real Utopias Project). London: Verso, 2003.

. Militants and citizens: the politics of participation in Porto Alegre.

Stanford:University Press, 2005.

BAQUERO, M. A vulnerabilidade dos partidos políticos e a crise da democracia na América Latina. Porto Alegre: Ed. Universidade/UFRGS, 2000.

CASANOVA, J. Public religions in the modern world. Chicago: University of Chicago Press, 1994.

COELHO, V. S. R. P. e VERISSIMO, J. Considerações sobre o processo de escolha dos representantes da sociedade civil nos conselhos de saúde em São Paulo. In: AVRITZER, Leonardo. (ed.). Participação em São Paulo. São Paulo: Unesp, 2004.

COELHO, V. S. R. P. Conselhos de saúde enquanto instituições políticas: o que está faltando? In: COELHO, SCHATTAN e NOBRE (eds.). Participação e Deliberação. São Paulo: 34Letras, 2004.

CORTES, S. M. V. "Construindo a possibilidade da participação dos usuários: conselhos e conferências no Sistema Único de Saúde". Sociologias, Porto Alegre, vol. 7, p. 2002.

COUTO, C. G. O Desafio de ser governo: o PT na Prefeitura de São Paulo (1989-1992). Rio de Janeiro: Paz e Terra, 1994.

DOIMO, A. M. Pluralidade religiosa à brasileira, associativismo e movimentos sociais em São Paulo. In: AVRITZER, L. (ed.). A participação em São Paulo. São Paulo: Editora UNESP, 2004.

ESCOREL, S. Reviravolta na saúde: origem e articulação do movimento sanitário. Rio de Janeiro: Editora FIOCRUZ, 1998.

1998.

Vidas ao Léu - trajetórias de exclusão social. Rio de Janeiro: FIOCRUZ,

FERNANDES, E. Direito Urbanístico e política urbana no Brasil: uma introdução. In: FERNANDES, E. (ed.). Direito Urbanístico e Política Urbana no Brasil. Belo Horizonte: Del Rey, 2001.

Do Código Civil de 1916 ao Estatuto da Cidade: algumas notas sobre a trajetória do Direito Urbanístico no Brasil. In: MATTOS, L. P. (ed.). Estatuto da Cidade Comentado. Belo Horizonte: Mandamentos, 2002. 
FUNG, ARCHON e WRIGHT, Erik O. (eds.). Deepening democracy: institutional innovations in empowered participatory governance. (Real Utopias Project). London: Verso, 2003.

GERSCHMAN, S. A democracia inconclusa: Um estudo da reforma sanitária brasileira. Rio de Janeiro: FIOCRUZ, 1995.

GOHN, M. G. M. Movimentos sociais e lutas pela moradia. São Paulo: Edições Loyola, 1991.

HELMKE, GRETCHEN, e LEVITSKY (eds.). Informal Institutions \& Democracy. Lessons from Latin America. Baltimore: John Hopkins UP, 2006.

HUNTINGTON, S. The clash of civilizations and the remaking of world order. New York: Simon \& Schuster, 1996.

JACOBI, P. Políticas públicas de saneamento básico e reivindicações sociais no município de São Paulo. 1974-1984. São Paulo: Editora: Cortez, 1986.

Environmental Problems Facing Urban Households in the City of São Paulo, Brazil.

Stockholm: Stockholm Environment Institute, 1995.

KECK, M. E. PT, A Lógica da diferença: o Partido dos Trabalhadores na construção da democracia brasileira. São Paulo: Editora Ática, 1991.

Press, 1992. . The workers party and democratization in Brazil. New Haven: Yale University

KOWARICK, L. Capitalismo e Marginalidade na América Latina. Rio de Janeiro: Paz e Terra, 1973.

MENEGUELLO, R. PT: A formação de um partido (1979-1982). Rio de Janeiro: Paz e Terra, 1989.

MEYER, JW, ROWAN, B. The new institutionalism in organizational analysis. The University of Chicago Press, 1991.

MILANI, C. R. S. “O princípio participativo na formulação de políticas públicas locais: análise comparativa de experiências européias e latino-americanas". In: ANPOCS, CD-Rom do XXIX Encontro da ANPOCS, Caxambu, 2005.

PEREIRA, M. L. D. L. "Repensando as relações entre espaço urbano e cidadania". Revista Arquitetura e Cultura, Belo Horizonte, vol. 3, 2002.

PITKIN, H. The Concept of Representation. Berkeley: University of California Press, 1967.

RÉOS, J. C Participação de usuários e responsáveis dos gestores de políticas sociais do município de Porto Alegre. Dissertação (Mestrado em Sociologia) - Universidade Federal do Rio Grande do Sul, Conselho Nacional de Desenvolvimento Científico e Tecnológico, 2003.

SADER, E.Quando novos personagens entraram em cena: experiências, falas e lutas dos trabalhadores da Grande São Paulo (1970-1980). Rio de Janeiro: Paz e Terra, 1988. 
SANTOS, B. de S. "Participatory Budgeting in Porto Alegre: Toward a Redistributive Democracy". Politics and Society, vol.4, 1998.

- Orçamento Participativo em Porto Alegre: para uma democracia distributiva. In: SANTOS, B. de S. Democratizar a Democracia. Rio de Janeiro: Civilização Brasileira, 2002.

SAULE, N. O Direito à cidade na Constituição de 1988. Legitimidade e eficácia do Plano Diretor. Dissertação de Mestrado em Direito. PUC-SP, São Paulo, 1995.

- "O Direito à cidade como paradigma da governança urbana democrática". Instituto Polis, 2005. Disponível em: < http://www.polis.org.br/artigo >. Acesso em 08 maio.2006.

SINGER, P. Um governo de esquerda para todos: Luiza Erundina na prefeitura de São Paulo (1989-1992). São Paulo: Brasiliense, 1993.

SINGER, P. e BRANDT, V. C. (orgs). São Paulo: O Povo em Movimento. Petrópolis: Editora Vozes, 1980.

SINTOMER, Y. e BACQUÉ, M.-H. (orgs.). Gestion de proximité et démocratie participative : une perspective comparative. Paris : La découverte, 2005.

UAMPA. A participação popular na administração municipal [Popular participation in municipal administration]. Porto Alegre: UAMPA, 1986.

WAMPLER, B. e AVRITZER, L. "Participatory publics: civil society and new institutions in democratic Brazil”. Comparative Politics, vol. 36, n³, 2004.

Recebido para publicação em novembro de 2007.

Aprovado para publicação em fevereiro de 2008. 